\section{A Thermostabile, Fungistatic Factor from Escherichia coli}

When cultivating Penicillium notatum Westl. and related fungi for the purpose of producing penicillin, it was soon noticed that the production of penicillin was inhibited by certain bacteria. It was proved that this was due to the fact that the bacteria in question formed an apparently enzymatic substance able to destroy penicillin. This substance, which was called penicillinase, was first demonstrated by Abraham and Chain ${ }^{1}$ in Esch. coli and $M$. lysodeikticus. It was later found in paracolon bacilli ${ }^{2}$, in $B$. subtilis ${ }^{3}{ }^{4}$, in penicillin-resistant staphylococc $i^{5}$, as well as in various other micro-organisms ${ }^{6,7,8}$. In addition, commercial preparations of taka-diastase and clarase were found to have a similar effect ${ }^{9,10}$. Preparations of penicillinase, like those of other enzymes, are more or less thermolabile. The penicillinase from Esch. coli, for example, is easily destroyed by heat ${ }^{1}$, whereas that from $B$. subtilis, on the other hand, seems to be more stable ${ }^{3}$.

Occasionally the production of penicillin was found to be partly or completely inhibited from other causes which could not be determined.

An interesting observation in this connexion was made here about two years ago in experiments with the cultivation of Penicillium notatum. In some cases, in which the nutrient medium was not sterilized immediately after its preparation, but was allowed to remain a short time at room temperature before autoclaving, the rate of growth of the fungus decreased, with the result that the production of penicillin also decreased. (Disturbances in the production of pigment by the fungus were also noted.) Evidently some'species of the micro-organisms which had developed before the medium was autoclaved had produced a thermostabile substance with fungistatic activity.

In later experiments to determine the ability of a number of bacteria to produce a substance of this kind, it was found that a strain of Esch. coli possessed this ability to a marked degree, particularly when the following medium was used: asparagine $2 \mathrm{gm}$., $\mathrm{NaNO}_{3} 3 \mathrm{gm}$., $\mathrm{KH}_{2} \mathrm{PO}_{4} 6.5 \mathrm{gm}$., $\mathrm{Na}_{2} \mathrm{HPO}_{4}, 12 \mathrm{H}_{2} \mathrm{O}$ 33.5 gm., $\mathrm{KCl} 0.5$ gm., $\mathrm{MgSO}_{4}, 7 \mathrm{H}_{2} \mathrm{O} \quad 0.5$ gm., $\mathrm{FeSO}_{4}, 7 \mathrm{H}_{2} \mathrm{O} 0.0 \mathrm{I}$ gm., glucose $40 \mathrm{gm}$., casein hydrolysate solution (Mueller) $2 \mathrm{ml}$, distilled water to 1 litre.

The growth of Penicillium notatum was excellent in this medium, which was sterilized by autoclaving at $120^{\circ} \mathrm{C}$. for twenty minutes, and after about seven days at room temperature a compact layer had been formed which completely covered the surface of the medium in the culture vessels. But, if after sterilization the medium was inoculated with Esch. coli, incubated at $37^{\circ} \mathrm{C}$. for 24 hours, and autoclaved again at $120^{\circ} \mathrm{C}$. for twenty minutes, the rate of growth of the fungus was found to be greatly reduced. Not until about seven days after inoculation could signs of growth be observed in the form of small, scattered, star-like, white figures around the wall of the vessel at the level of the surface of the medium. The later growth was also very slow.

The differences in the sugar concentration and the $p H$, respectively, between the medium in which $E s c h$. coli had been cultivated and the original medium were not significant, and the reduction in the rate of growth can therefore not have been due to any variation in these respects. It was also proved that with the exception of the inoculation with Esch. coli the treatment of the medium (incubation at $37^{\circ} \mathrm{C}$. and autoclaving) did not cause the inhibition of growth. Since all the substances necessary for normal growth were present, some fungistatic factor, which also was thermostable, must have been produced.

This fungistatic factor can be produced in other media also, for example, broth, but not to the same extent as in that stated above.

The factor in question was found to be without any effect in the assay of penieillin by the cylinder-plate method (modified according to Wiedling ${ }^{11}$ ). It thus differs from penicillinase not only in its thermostability, but also in that its effect on the production of penicillin is caused by a reduction in the rate of growth of the fungus and not by actual destruction of the penicillin. The thermostability of the factor also distinguishes it from most other bacterial fungistatics, which usually are thermolabile ${ }^{12}$.

Central Laboratories of AB. Astra, Sten Wiedurng. Södertälje, Sweden. April 28.

'Abraham, E. P., and Chain, E., Nature, 146, 837 (1940).

- Harper, G. J., Lancet, ii, 569 (1943).

s Duthie, E. S., Brit. J. Exp. Path., 25, 96 (1944).

- Ungar, J., Nature, 154, 236 (1944).

- Kirby, W. M. M., Science, 99, 452 (1944).

- Woodruff, H. B., and Foster, J. W., J. Bact., 47, 425 (1944).

'Bondi, A., jun., and Dietz, C. C., J. Bact., 47, 426 (1944).

8 Himes, A. T., and White, H. J., J. Bact., 47, 426 (1944).

- Lawrence, C. A., Science, 98, 413 (1943).

${ }^{10}$ Lawrence, C. A., Science, 99, 15 (1944).

11 Wiedling, S., Bot. Not., 433 (1944).

1. Fries, N., Symb. Bot. Ups., iii, No. 2, 25 (1938),

\section{A New Occurrence of the Electronic Phase Velocity}

STARTING with the Lorentz equation :

$$
\frac{d}{d t}(m \mathbf{v})=e\left\{\mathbf{E}+\frac{[\mathbf{v H}]}{c}\right\}
$$

we have, after scalar multiplication by $\mathbf{v}$, which is at right angles to the vector product $[\mathbf{v}, \mathbf{H}]$,

$$
\frac{d}{d t}\left(\frac{1}{2} m v^{2}\right)=e \mathbf{v E} \text {. }
$$

Replacing $\mathbf{E}$ in terms of $\varphi$ and $\mathbf{A}$,

$$
\frac{d}{d t}\left(\frac{1}{2} m v^{2}\right)=-e\left(\mathbf{v} \nabla \varphi+\frac{\mathbf{v} \dot{\mathbf{A}}}{c}\right) ; .
$$

where $\mathbf{A}$, the vector potential, satisfies

$$
\mathbf{H}=\operatorname{curl} \mathbf{A} \text { and } \nabla A+\dot{\phi} / c=0 . .
$$

We next write in (3) for its rearrangement

$$
\mathbf{v} \nabla \varphi=\frac{d \varphi}{d t}-\dot{\varphi}, \cdot \cdot \cdot \cdot \cdot \cdot
$$

so that the total energy changes at the rate

$$
\frac{d}{d t}\left(\frac{1}{2} m v^{2}+e \varphi\right)=e \dot{\varphi}-\frac{e \mathbf{v} \dot{\mathbf{A}}}{c} . .
$$

Now, using (4), this may be written

$$
\frac{d}{d t}\left(\frac{1}{2} m v^{2}+e \varphi\right)=-e c\left(\nabla \mathbf{A}+\frac{\mathbf{v}}{c^{2}} \dot{\mathbf{A}}\right) .
$$

Next, let us seek the consequences of supposing $\left(\frac{1}{2} m v^{2}+e \varphi\right)$ to be constant, both in space and time. This means, from (7),

$$
\nabla \mathbf{A}+\frac{\mathbf{v} \dot{\mathbf{A}}}{c^{2}}=0 ; \quad \cdot \quad . \quad .
$$

